\title{
Static or Dynamic Efficiency: Horizontal Merger Effects in the Wireless Telecommunications Industry
}

\author{
M. Grajek ${ }^{1} \cdot$ K. Gugler ${ }^{2}$ (D) T. Kretschmer ${ }^{3,4} \cdot$ I. Mişcişin ${ }^{5}$
}

Published online: 23 August 2019

(c) The Author(s) 2019

\begin{abstract}
This paper studies five mergers in the European wireless telecommunication industry and analyzes their impact on prices and capital expenditures of both merging carriers and their rivals. We find substantial heterogeneity in the relationship between increases in concentration and carriers' prices. The specifics of each merger case clearly matter. Moreover, we find a positive correlation between the price and the investment effect; when the prices after a merger increase (decrease), the investments increase (decrease) too. Thus, we document a trade-off between static and dynamic efficiency of mergers.
\end{abstract}

Keywords Telecom mergers · Static and dynamic efficiency $\cdot$ Difference-indifference

JEL Classification $\mathrm{L} 22 \cdot \mathrm{O} 33 \cdot \mathrm{G} 34 \cdot \mathrm{L} 96$

K. Gugler

klaus.gugler@wu.ac.at

M. Grajek

michal.grajek@esmt.org

T. Kretschmer

t.kretschmer@1mu.de

I. Mişcişin

ion.miscisin@univie.ac.at

1 ESMT Berlin, Schlossplatz 1, 10178 Berlin, Germany

2 WU (Vienna University of Economics and Business), Welthandelsplatz 1, 1020 Vienna, Austria

3 Munich School of Management, Ludwig-Maximilians-Universität München, Kaulbachstr. 45, 80539 Munich, Germany

4 Centre for Economic Policy Research (CEPR), London, UK

5 University of Vienna, Oskar-Morgenstern-Platz 1, 1090 Vienna, Austria 


\section{Introduction}

Market structure has an important effect on the static and dynamic efficiency of markets. A standard microeconomic argument suggests that a more competitive market puts more pressure on firms to exploit ways to reduce production costs and increase efficiency. Firms will face low profits and therefore will try to "escape competition" (Aghion et al. 2005) by reducing their cost of production. However, the incentives to invest will not only affect static efficiency (in the form of lower prices), but also dynamic efficiency (in the form of increased investment in long-term improvements). In concentrated markets, mergers and acquisitions will affect market structure significantly. Consequently, the behavior of firms may well change as a result of a merger in the industry, both for the merging and the non-merging firms. Hence, we study whether and how indicators of static and dynamic efficiency are affected by a merger in the industry.

Therefore, the core questions that we ask in this paper are whether within-market mergers have led to increased static and/or dynamic efficiency, and whether there is a tradeoff between the two. The answers to these questions will be relevant both to policymakers and to firms that operate within such industries. ${ }^{1}$ Policymakers will pursue dual goals of static and dynamic efficiency, but may place different weights on either. Further, firms that operate in technologically intensive industries may incorporate the expected short- and long-term effects of mergers on their own and their rivals' efficiency in their decisions to merge.

At the time that this article was written, a four-to-three merger in the US wireless telecom market was being scrutinized by the regulators. The proposed deal ${ }^{2}$ involves T-Mobile US and Sprint: which are the two smallest carriers on the market, with the respective market shares of $16 \%$ and $12 \%$ and with the combined market share still falling behind those of the two biggest players, AT\&T and Verizon. The previous attempts by the same operators, as well as an earlier bid by AT\&T to acquire T-Mobile, failed, as the regulators feared it would lead to higher prices for consumers. The new bid is defended on the grounds that the merged entity pledges to invest at least USD 40 billion and to build a 5G network faster than the other two competitors, which requires combining the spectrum assets of both carriers. This highlights the trade-off between higher prices (market power effect) and higher quality (investment effect), which is considered in this article, and the relevance of our findings for the competition policy.

We study these issues in the wireless telecoms sector in Europe. The markets in this sector can be characterized as still national in scope. They display large market concentration, and are in need of large sunk investments. This is a useful setting

\footnotetext{
1 Williamson (1968) was one of the first to consider the trade-off between higher prices and efficiencies that are faced by a regulator when reviewing a merger, and thus to emphasize the role of economies as a merger defense.

2 See "T-Mobile and Sprint chivvy regulators to bless their merger" in The Economist, May 3, 2018: https://www.economist.com/business/2018/05/03/t-mobile-and-sprint-chivvy-regulators-to-bless-their -merger.
} 
because market definition and identification of market participants are easy, and because there have been a series of important mergers in different countries that we observe. Moreover, the telecoms sector is an important part of most advanced economies, both for its direct effect of economic growth, but also for its general purpose technology characteristics (Röller and Waverman 2001; Czernich et al. 2011).

In addition, the trade-off between static and dynamic efficiencies is especially relevant in an industry with significant technological progress, both in terms of infrastructure and in terms of services. A Merrill Lynch report mentions that carriers are being pushed "to seek efficiencies in many areas: network construction and operation (via network sharing and outsourcing), marketing and distribution (via simplified, SIM-only rate plans) and product/development/support (by de-emphasizing walled garden content and services). These trends are being furthered by technology (smarter smartphones that reduce the need for specialized carrier-provided content) and regulation (pushing carriers to de-emphasize early termination fees)."3

The conventional approach for studying the effects of mergers on firm behavior is a cross-country study that compares markets with mergers to those without a merger. Such studies are informative, but they have several weaknesses: First, a comparison of markets with and markets without mergers may mask several aspects and could, for example, interpret ex-ante heterogeneity across markets that affects the likelihood of mergers as causal drivers of efficiency increases ex-post: following a merger. Second, obtaining one average effect of mergers across countries may be misleading if there is substantial heterogeneity of effects across countries. Even within countries, the merging firms and the rival firms may react differently to a merger.

We therefore choose a multiple-single-case approach: We study five mergers in four European countries that increased market concentration considerably ${ }^{4}$ and we examine the effects of mergers on two outcomes: prices as a measure of static efficiency, which is determined by the current firm's market power and costs; and capital expenditures as a measure of the firms' investment incentives. While we have no way of statistically comparing the five cases, we see interesting patterns: In two of the five cases, the effect on static efficiency is positive; in two, it is negative (in one it is insignificant); but in nearly all scenarios, the merging as well as rival firms' prices moved mostly in the same direction.

Moreover, we find a positive correlation between the price and the investment effects. In the markets with an increase in price (i.e., a decline in static efficiency), all firms reported an increase in capital expenditure, which suggests a stronger focus on dynamic efficiency; the opposite effect prevails in the markets where there was a decrease in prices after a merger.

These findings suggest a tradeoff between static and dynamic efficiency: While two countries provide indicative evidence for an increase in static efficiency at the

\footnotetext{
3 Global Wireless Matrix 1Q10. BofA Merrill Lynch.

${ }^{4}$ Of these five mergers two reduce the number of firms from four to three (4-to-3) and three involve reductions from 5-to-4 firms. There were two mergers in the Netherlands: 5-to-4 and then 4-to-3; and one merger each in Austria, Denmark, and Greece.
} 
expense of less investments, the other two displayed higher investments into future infrastructure at the expense of higher post-merger prices.

In a narrow sense, we contribute to the literature on merger effects, especially in the telecommunications industry. However, our results make two broader points: (1) Mergers have to be assessed for their static and dynamic effects on the evolution of an industry; and (2) The effects of mergers are highly context-specific, even in the same industry.

From a policy perspective, it is also notable that competition policy may interact with science and technology policy in the sense that investments for infrastructure may be affected by competition policy instruments. This calls for an integrated view on these two policy aspects.

Finally, we also contribute to the literature on firms' innovation strategies (e.g. Coad and Rao 2008; Beneito 2003; and De Faria et al. 2010), which reiterates the important point that market structure affects innovation performance, but also suggests that the choice of partner-in our case through a merger-may be crucial for successful innovation.

\section{Prior Literature}

Merger effects have been widely studied across multiple academic fields, such as economics, management and finance. A significant number of economic studies focus on consumer welfare and find anti-competitive effects of mergers in many industries (e.g., McCabe 2002, in the journal market, and Dafny 2009, in the hospital market). Weinberg (2007) surveys the economics literature on this topic and finds that most mergers that have been examined by this literature resulted in increased prices, at least in the short term, which defines them as anti-competitive. Such shortterm effects of increased pricing power due to mergers are also confirmed in the strategy literature (e.g., Moatti et al. 2015, in global retail industry).

Further, there are a number of studies that conclude that merger-related efficiencies can outweigh the increase in market power, which thereby render the mergers pro-competitive-especially in the longer term. For instance, Focarelli and Panetta (2003) find that the short-term price increases that are due to mergers were followed by reduction of prices in the longer term in the banking industry in Italy. Also, Connor et al. (1998) show that the average costs and prices increased less for the US hospitals that were involved in a merger.

More generally, longer term, dynamic merger efficiencies, were often studied in terms of the impact of mergers on firms' investment and innovation (Morgan 2001). Early economic literature on this topic-which is surveyed in Cohen and Levin (1989) and Scherer (1998)—seems largely inconclusive. More recent work in the management field does not yield unambiguous results that could easily be generalized across many sectors of the economy either (e.g., Hitt et al. 1996; Zhao 2009; Valentini 2012). Two explanations of the inability to find general conclusions about the role of mergers for dynamic efficiency are that (1) the effects may not be linear (Aghion et al. 2005; Cloodt et al. 2006; Sacco and Schmutzler 2011); and (2) there 
may be substantial heterogeneity in the way dynamic efficiencies are realized across industries (Morgan 2001) and firms (Desyllas and Hughes 2010; Wagner 2011).

This paper adds to this literature a simultaneous analysis of static and dynamic efficiencies by investigating pricing and investments in the specific context of mobile telecoms' mergers. This allows us, among other things, to study potential trade-offs between the static and dynamic efficiencies.

As observed by Morgan, "it is clear from the emerging literature on the treatment of competition to innovate that different issues will arise in different industrial settings" (Morgan 2001, p. 182).

In our context most important dynamic efficiencies are in the area of enabling future innovation in various sectors of the economy using mobile telecommunications - in particular mobile internet access and data services-as inputs. The impact of telecommunications on innovation and economic growth is well documented (see e.g., Röller and Waverman 2001; Czernich et al. 2011) and can even be expected to grow over time, as mobile data services are increasingly enabled, in line with the general purpose technology paradigm (Bresnahan and Trajtenberg 1995).

As a consequence, the measure of dynamic efficiency in our context is best captured by investment in infrastructure, rather than R\&D spending (e.g., Hitt et al. 1996; Cassiman et al. 2005; Szücs 2014), or patenting (e.g., Zhao 2009; Valentini 2012), which are crucial in other contexts, such as the pharmaceutical industry. Further, and related to this point, the dynamic merger effects in our context are more likely to be related to market power and/or efficiency gains (see e.g., Chatterjee 1986; Seth 1990) rather than transfer of knowledge (see e.g., Ahuja and Katila 2001).

Thus, the main contribution of this paper is to add to the literature on market concentration and investment in the telecommunication industry: which is an important driver of overall economy innovation and growth. By pursuing this goal we also aim to foster our understanding of how competition policy, which governs market concentration to a significant extent, may interact with science and other technologyrelated policies to facilitate technological progress.

Genakos et al. (2018) in a study that is similar to ours use the Teligen dataset, which contains information on usage-specific tariffs for the two largest operators in each market, ${ }^{5}$ to investigate the impact of the industry structure on prices and capital expenditures. They find that an increase in market concentration leads to both higher prices and per-operator investment, but has no statistically significant effect on the investment on the market level.

The difference of our approach is that by using a dataset that is less restrictive in terms of the number of covered operators we are able to look at each of the cases separately and thus account for merger heterogeneity. On the other hand, this comes at a cost of having a less precise price measure. Thus our studies are complementary.

\footnotetext{
5 Teligen collects data on all tariffs of the two largest operators and computes the cost to a customer of hypothetical usage profiles that are essentially consumer baskets of a fixed number and duration of voice calls and text messages.
} 
There also exists some indirect empirical evidence of it from fixed-line telecom markets. In particular, the increase in competition from entrant telecom operators that was enabled by the U.S. Telecommunications Act of 1996, was found to bring differentiation of service offerings (Greenstein and Mazzeo 2006) and new price plan introductions (Economides et al. 2008). New entry that was facilitated by the mandated access to European incumbent operators' infrastructure was also shown to bring differentiation of broadband access speed (Nardotto et al. 2015), but lower investment at both the industry and the operator level (Grajek and Röller 2012).

Our analysis also follows the finance literature (Eckbo 1983; Stillman 1983) by allowing for differential effects of mergers on the merging parties and their industry rivals. Indeed, such differential effect of mergers on prices and profitability is typically used to distinguish pro-competitive mergers - which are characterized largely by efficiency-based synergies from anti-competitive mergers-which are characterized largely by market power-based price increases (e.g., Duso et al. 2007; Clougherty and Duso 2011; Gugler and Szücs 2016). A similar approach was used to study the profitability of alliances (Oxley et al. 2009), responses to hostile takeover attempts (Servaes and Tamayo 2013), and the effects of mergers on R\&D spending (Szücs 2014). In our context, the differential effect of mergers across firms in the same market allows for more precise inference about potential trade-offs between static and dynamic efficiencies.

Finally, we also contribute to the literature on firms' innovation strategies. Coad and Rao (2008) examine the linkage between innovation and firm growth in hightech sectors and find that-relative to an average firm that experiences only modest returns - innovation is of great importance for the fastest-growing firms. Beneito (2003) provides an empirical analysis of firms' decision when choosing among R\&D investment strategies. De Faria et al. (2010) study cooperation in innovation activities and find that the firms in the high-tech sectors, with higher levels of absorptive capacity, exports and innovation intensity are more likely to cooperate in the innovation process and place greater value on their innovation cooperation partners. We show that mergers that reduce the market price pressure allow firms to focus on investments into long-term improvements.

\section{Data}

We construct our dataset by using two major sources: the Global Wireless Matrix dataset that is provided by Merrill Lynch (ML) and the World Cellular Information Service that is provided by Informa (EMC). Our dataset covers quarterly observations on 62 operators in 17 countries for the period from the last quarter of 1998 to the second quarter of 2011. The dataset contains information on: the size of the customer base (the number of mobile phone users); usage intensity measured by the number of minutes of use; revenues; and investments. This information is used to construct our key variables of interest, which are listed in Table 1. The summary statistics are presented in Table 2.

Our first dependent variable-revenue per minute (RPM) - is calculated by dividing the monthly voice-only service revenues by the total minutes of use on an 
Table 1 Variables' description

\begin{tabular}{ll}
\hline Variable & Explanation \\
\hline RPM $_{i j t}$ & Price of carrier $i$ in market $j$ in period $t$, defined as revenue per minute (RPM), EUR \\
Capex $_{i j t}$ & Capital expenditure (Capex) of carrier $i$ in the market $j$ in period $t$, mln EUR \\
MOU $_{i j t}$ & Average minutes of use (MOU) on carrier $i$ 's network in market $j$ in period $t$, minutes \\
MobPen $_{i j t}$ & Number of carrier $i$ 's users relative to country's population in market $j$ in period $t$ \\
FixPen $_{j t}$ & Number of fixed line users relative to country's population in market $j$ in period $t$ \\
$G D P_{j t}$ & GDP per capita in market $j$ in period $t$, EUR \\
\hline
\end{tabular}

Table 2 Summary statistics

\begin{tabular}{llllll}
\hline Variable & Mean & SD & Min. & Max. & N \\
\hline Revenue per minute (RPM) & 0.215 & 0.111 & 0.04 & 1.056 & 2170 \\
Capital expenditure (Capex) & 82.111 & 86.927 & 1.96 & 764 & 1597 \\
Minutes of use (MOU) & 143.405 & 48.753 & 44 & 334 & 2201 \\
Mobile penetration rate (MobPen) & 0.265 & 0.162 & 0 & 0.823 & 2929 \\
Fixed penetration rate (FixPen) & 0.499 & 0.13 & 0.179 & 0.74 & 3170 \\
GDP per capita (GDP) & 28,533 & 11,918 & 5835 & 70,314 & 3145 \\
\hline
\end{tabular}

operator's network. Service revenues include monthly service charges and usage fees, roaming, long distance, and subscriptions to mobile data services, but exclude equipment and accessories, and are adjusted for inflation by using Eurostat's consumer price index. ${ }^{6}$ RPM is usually not disclosed by operators, but is calculated by Merrill Lynch, because it arguably constitutes a better proxy for pricing than the average revenue per user (ARPU) commonly reported by operators. ${ }^{7}$ The average RPM in our sample is 21.5 Euro cents and follows a downward trend over time, as shown in Fig. 1.

Many previous studies of the wireless telecommunications sector relied on Teligen data, which are different from ours in several respects: Teligen data come in the form of a customer bill that corresponds to a particular usage profile (low, medium, high) that remains fixed over time. These expenditures are computed by picking the cheapest available tariff for each profile. However, these data are available only for the two biggest operators in each country. Therefore, our data have the advantage of allowing us to analyze the pricing behavior of both the merging carriers and their rivals. This comes at the cost of having a more coarse price measure.

\footnotetext{
${ }^{6}$ Merrill Lynch admits, however, that some operators also include non-service revenues (e.g. equipment sales) in their revenue calculation, while others exclude revenues from roaming by pre-paid card users or from incoming traffic.

${ }^{7}$ ARPU is calculated by dividing service revenues by the average subscriber base. We adopt RPM as our main dependent variable and use ARPU for robustness checks. The results, which are available upon request, are not sensitive to the price definition.
} 


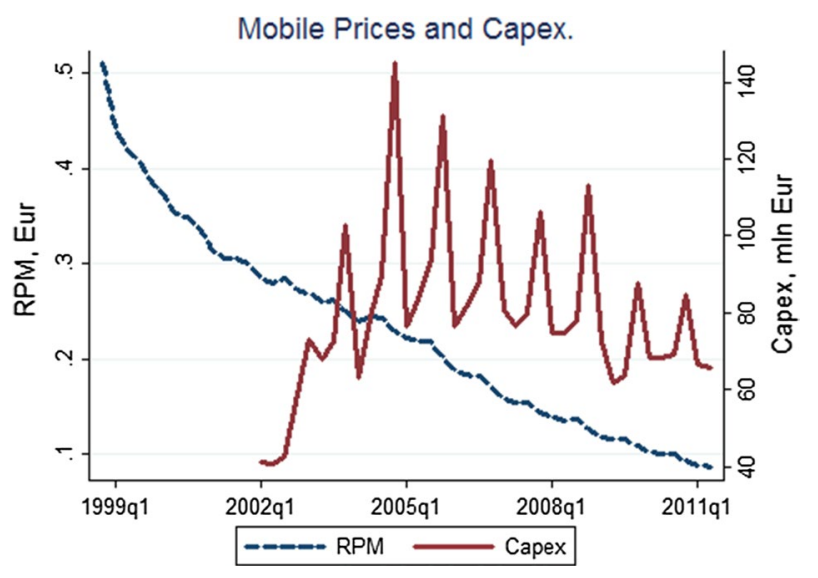

Fig. 1 Evolution of mobile prices and Capex, 1998-2011

Our second dependent variable is operator's capital expenditure (Capex). Since innovation in the provision of mobile telecommunications services over the period of our sample was mostly driven by the increased reliability of services coupled with increased speed of mobile data transmission, it is well captured by the Capex: a close proxy for the network build-up. As is shown in Fig. 1, Capex follows a nonlinear trend over time and is highly seasonal in our sample. The Capex series that are reported by Merrill Lynch start only in the first quarter of 2002, which limits the number of observations we can use to study the operators' investment behavior.

The average monthly usage time per user (MOU), mobile and fixed penetration rates, and GDP per capita serve as control variables in our analysis. MOU is calculated by dividing the total monthly usage on an operator's network by the average subscriber base. It is measured in minutes and usually excludes traffic that is related to mobile data services, but counts both incoming and outgoing minutes of use. The average MOU in our sample is 143.4 min per month. It controls for changes in our price measures (RPM and ARPU) that result from the changing intensity of use of mobile phones - for instance due to fixed-mobile substitution, rather than genuine changes in the price plans. ${ }^{8}$ Mobile and fixed penetration rates are defined as the number of cellular users of a given carrier and the number of fixed-line users (or fixed lines) in a given country divided by that country's population, respectively. The former controls for possibly different pricing strategies that are used by small versus large mobile network operators; e.g., penetration pricing may more often be used by the small operators. GDP per capita-which is routinely used as a demand shifter control-is adjusted for inflation by using the Eurostat's consumer price index.

\footnotetext{
${ }^{8}$ This control is arguably more important for ARPU, which we use as a price measure in our robustness checks.
} 


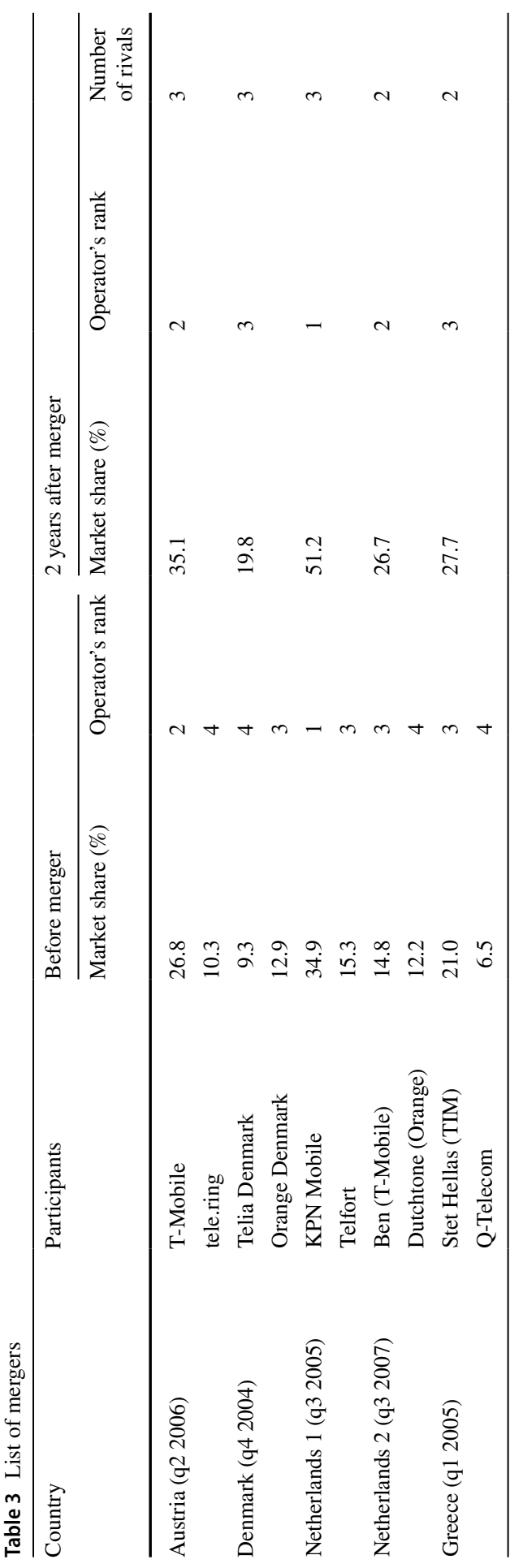


In the time period of our analysis we observe five horizontal mergers. ${ }^{9}$ Table 3 lists the analyzed mergers and reports the characteristics of the operators that were involved: their individual market shares (in terms of users) at the moment of the merger; their rank according to their size among all carriers active in the corresponding national markets; the market share and the rank of the merged firm 2 years after the merger; and the number of the operators that remain. While there is substantial heterogeneity in terms of these characteristics across cases, all mergers lead to substantial increases in market concentration.

\section{Methodology and Results}

We adopt a difference-in-difference approach to investigate differences in pricing and investment between the merging firms and the rest of the market. The diff-in-diff approach looks at changes in these differences after the merger takes place. A similar methodology, for instance, is used by McCabe (2002), who looks at the mergers of scientific journals. Our approach differs in that we explicitly exclude the competitors in the own market from the control group to avoid contamination of the control group by merger spillovers. For instance, if a merger reduces the competitive rivalry in a given market, both the merging parties and the rivals may respond by increasing their prices. In the context of the wireless industry, due to the institutional and regulatory setup, each national market constitutes a relevant market. Thus, our control group consists of operators in markets where no merger took place. ${ }^{10}$

We define our pricing model as:

$$
\begin{aligned}
\text { RPM }_{i j t}= & \alpha_{0}+\alpha_{1} * \text { Merging }_{j t}+\alpha_{2} * \text { MOU }_{i j t}+\alpha_{3} * \text { MobPen }_{i j t} \\
& +\alpha_{4} * \text { FixPen }_{j t}+\alpha_{5} * G D P_{j t}+c_{j}+\tau_{t}+\epsilon_{i j t}
\end{aligned}
$$

and

$$
\begin{aligned}
R P M_{i j t}= & \beta_{0}+\beta_{1} * \text { Rival }_{j t}+\beta_{2} * M O U_{i j t}+\beta_{3} * \text { MobPen }_{i j t} \\
& +\beta_{4} * \text { FixPen }_{j t}+\beta_{5} * G D P_{j t}+d_{j}+\phi_{t}+v_{i j t} .
\end{aligned}
$$

In both equations: $i$ indicates a firm; $j$ indicates a market and $t$ indicates a time period. We write the pricing model as two separate equations to stress the fact that the equations are estimated using different samples: We drop all rival firms to all mergers when estimating (1); and we drop all merging firms when estimating (2).

\footnotetext{
9 Due to the insufficiency of data on prices, the merger in Finland that occurred during the time period analyzed in this study was excluded.

${ }^{10}$ Whether that constitutes a proper comparison group depends on the plausibility of the assumption that, following the merger, the trend of the unobserved counterfactual would remain parallel to that of the control group, which in general is impossible to test. However, one indication that this requirement does indeed hold is the fact that both trends are parallel in the pre-merger period, which in conjunction with the assumption of no cross-market spillovers and no other structural change with differential impacts on the treatment and control groups suggests that our difference-in-difference results are reliable. A visual inspection of the trends suggests that this is the case (we attach the corresponding figures in "Appen$\operatorname{dix} 1 ")$.
} 
Moreover, to obtain merger-specific coefficients for each merger in our data, we estimate the pricing model (1) and (2) five times: with each set of the merging firms (or rivals) as a separate treatment group. Estimated this way, the effects of mergers on merging firms [in (1)] and on rivals [in (2)] are in each case relative to the same control group: all firms in markets that did not experience a merger.

Merging $_{j t}$ and Rival $_{j t}$ are both dummy variables that are defined as the interac-

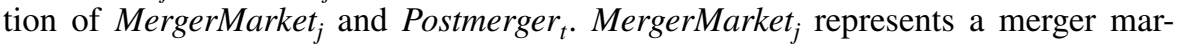
ket dummy variable and is used to control for the systematic difference in prices between the merging (or rival) firms and the control group (firms in markets with no mergers). Postmerger ${ }_{t}=1$ for all periods $t$ after the merger and otherwise 0 . $\operatorname{Merging}_{j t}\left(\right.$ Rival $\left._{j t}\right)$ thus measures the change in the difference in prices between the merging firms (rivals) and the control group, subsequent to the merger. Thus, the coefficients on these variables represent the merger effects on the merging and rival firms, respectively. ${ }^{11}$

In the pricing model we also control for: the minutes of use $\left(M O U_{i j t}\right)$; mobile user penetration $\left(\mathrm{MobPen}_{i j t}\right)$; fixed line penetration $\left(\right.$ FixPen $\left._{j t}\right)$; and GDP per capita $\left(G D P_{j t}\right)$. As was explained in the previous section, $M O U_{i j t}$ captures an average volume effect, whereby users who call more minutes pay usually a lower price per minute. $M_{o b P e n}$ controls for possible effects of market dominance (measured by the percentage of population that is accounted for by an operator) on pricing strategy. FixPen ${ }_{j t}$ controls for competition from fixed-line telephony and $G D P_{j t}$ for shifts in overall demand, which both may influence mobile telephony pricing. We also include country dummies and time period dummies in both equations. ${ }^{12}$

To measure dynamic effects of mergers, we investigate levels of investment in addition to the operators' pricing. The model's specification is as before, except for the dependent variable, which is now capital expenditure: ${ }^{13}$

$$
\begin{aligned}
\log _{\left(\text {Capex }_{i j t}\right)=} & \gamma_{0}+\gamma_{1} * \text { Merging }_{j t}+\gamma_{2} * \operatorname{MOU}_{i j t} \\
& +\gamma_{3} * \text { MobPen }_{i j t}+\gamma_{4} * \text { FixPen }_{j t}+\gamma_{5} * G D P_{j t}+l_{j}+\lambda_{t}+\xi_{i j t}
\end{aligned}
$$

and

$$
\begin{aligned}
\log \left(\operatorname{Capex}_{i j t}\right)= & \delta_{0}+\delta_{1} * \operatorname{Rival}_{j t}+\delta_{2} * \operatorname{MOU}_{i j t} \\
& +\delta_{3} * \operatorname{MobPen}_{i j t}+\delta_{4} * \text { FixPen }_{j t}+\delta_{5} * G D P_{j t}+m_{j}+\psi_{t}+v_{i j t}
\end{aligned}
$$

The investment model is specified analogously to the pricing model. Thus, the treatment and the control groups, the main variables of interest and the control variables in (3) and (4) are the same as in (1) and (2). Unlike in the pricing model, however,

\footnotetext{
11 In order for the time series to be consistent, we generate a composite entity by averaging pre-merger observations, with the use of the respective market shares as weights, for the operators that merge.

12 Note that Postmerger $_{t}$ and Merger ${ }_{j}$ are omitted from the Eqs. (1) and (2), because the former is colinear with time period and the latter with the country dummy variables.

13 The log-linear specification was chosen here because the level of Capex (unlike price) depends on the market's size.
} 
Table 4 Price and investment effects of the Austrian merger

\begin{tabular}{|c|c|c|c|c|c|c|c|c|}
\hline & \multicolumn{4}{|l|}{ RPM } & \multicolumn{4}{|l|}{ Capex } \\
\hline & \multicolumn{2}{|l|}{ Merging } & \multicolumn{2}{|l|}{ Rivals } & \multicolumn{2}{|l|}{ Merging } & \multicolumn{2}{|l|}{ Rivals } \\
\hline & Coeff. & SE & Coeff. & SE & Coeff. & SE & Coeff. & SE \\
\hline Merging/Rival & 0.006 & 0.006 & $-0.061 * * *$ & 0.006 & $-0.297^{*}$ & 0.130 & $-0.333 * *$ & 0.123 \\
\hline Minutes of Use & $-0.000 * * *$ & 0.000 & $-0.000 * * *$ & 0.000 & $0.003 * * *$ & 0.001 & $0.003 * * *$ & 0.001 \\
\hline Mobile Penetration & -0.006 & 0.008 & -0.008 & 0.008 & $1.348 * * *$ & 0.137 & $1.352 * * *$ & 0.137 \\
\hline Fixed Penetration & 0.035 & 0.022 & 0.033 & 0.022 & $0.762 *$ & 0.328 & $0.748^{*}$ & 0.328 \\
\hline GDP p.c. & $0.002 * * *$ & 0.000 & $0.002 * * *$ & 0.000 & $0.012 *$ & 0.005 & $0.012 *$ & 0.005 \\
\hline Number of obs & 1690 & & 1691 & & 1064 & & 1064 & \\
\hline F-statistic & 197.238 & & 198.790 & & 90.220 & & 89.294 & \\
\hline F-test $p$ value & 0.000 & & 0.000 & & 0.000 & & 0.000 & \\
\hline R-squared & 0.867 & & 0.871 & & 0.808 & & 0.808 & \\
\hline Root MSE & 0.038 & & 0.038 & & 0.458 & & 0.457 & \\
\hline
\end{tabular}

Merging/Rival represents the treatment dummy variable: It equals 1 in the post-merger period for the merging firm in the Merging pane and for rival firms in the Rivals pane

$* p<0.05 ; * * p<0.01 ; * * * p<0.001$

the Capex of the pre-merger entities is defined as a sum, rather than an average, of the Capex expenditures by the acquirer and the target.

\subsection{Austria}

The merger in Austria involved T-Mobile-which is owned by the German Deutsche Telekom and accounted for approximately $25 \%$ of the market-acquiring tele.ring: a price-aggressive maverick that doubled its market share in the 3 years prior to the merger and came to control $10 \%$ of the market. Due to its competitive behavior, tele. ring was believed to exert more competitive pressure on its rivals than its market share would suggest. In its decision, the European competition authority identified non-coordinated effects and could not rule out coordinated effects that could result from the merger; but the authority cleared it subject to remedies. T-Mobile committed to sell some of its mobile sites to the other operators (in particular to $\mathrm{H} 3 \mathrm{G}$, the smallest carrier on the market that was lacking network infrastructure and frequencies necessary to challenge the other operators) and either sell or return a frequency package. $^{14}$

The estimation results for the Austrian market (Table 4) suggest that, while in general prices for the mobile services experienced a downward trend in the postmerger period (see Appendix 2), post-merger prices in Austria declined also relative

\footnotetext{
14 Case No COMP/M.3916. T-MOBILE AUSTRIA/TELE.RING. Commission decision of April 26, 2006, available at http://ec.europa.eu/competition/mergers/cases/decisions/m3916_20060426_20600 _en.pdf.
} 
Table 5 Price and investment effects of the Danish merger

\begin{tabular}{|c|c|c|c|c|c|c|c|c|}
\hline & \multicolumn{4}{|l|}{ RPM } & \multicolumn{4}{|l|}{ Capex } \\
\hline & \multicolumn{2}{|l|}{ Merging } & \multicolumn{2}{|l|}{ Rivals } & \multicolumn{2}{|l|}{ Merging } & \multicolumn{2}{|l|}{ Rivals } \\
\hline & Coeff. & SE & Coeff. & SE & Coeff. & SE & Coeff. & SE \\
\hline Merging/Rival & $0.073 * * *$ & 0.012 & $0.060 * * *$ & 0.008 & $0.470 * * *$ & 0.130 & $0.310 * *$ & 0.103 \\
\hline Minutes of Use & $-0.000 * * *$ & 0.000 & $-0.001 * * *$ & 0.000 & $0.003 * * *$ & 0.001 & $0.002 * * *$ & 0.001 \\
\hline Mobile Penetration & -0.008 & 0.008 & -0.010 & 0.008 & $1.349 * * *$ & 0.137 & $1.366^{* * * *}$ & 0.135 \\
\hline Fixed Penetration & 0.020 & 0.022 & 0.008 & 0.021 & 0.526 & 0.317 & 0.412 & 0.326 \\
\hline GDP p.c. & $0.002 * * *$ & 0.000 & $0.002 * * *$ & 0.000 & 0.010 & 0.005 & 0.009 & 0.005 \\
\hline Number of obs & 1678 & & 1729 & & 1064 & & 1094 & \\
\hline F-statistic & 165.963 & & 166.209 & & 106.491 & & 99.693 & \\
\hline F-test $p$ value & 0.000 & & 0.000 & & 0.000 & & 0.000 & \\
\hline R-squared & 0.863 & & 0.861 & & 0.822 & & 0.813 & \\
\hline Root MSE & 0.038 & & 0.038 & & 0.459 & & 0.458 & \\
\hline
\end{tabular}

Merging/Rival represents the treatment dummy: it equals 1 in the post-merger period for the merging firm in the Merging pane and for rival firms in the Rivals pane

$* p<0.05 ; * * p<0.01 ; * * * p<0.001$

to the control group. These results are in line with Aguzzoni et al. (2015) that finds that on aggregate there was a statistically significant price decrease in the range of $-2 \%$ to $-20 \%$ as a result of this merger in Austria. Our results further suggest that the price reaction to the merger was to a larger extent driven by the rivals, as can be seen by the magnitude and significance of the Merging/Rival coefficient in the RPM equations. At the same time we find that the merger had a statistically significant negative effect on investment by both the merging firms and the rivals.

We thus observe a tradeoff between the static and dynamic efficiencies in the Austrian merger case: The lower prices that were charged by the operators after the merger increased the static efficiency in the market; this effect was countered by a drop in capital expenditures, however, which we interpret as a decrease in dynamic efficiency.

\subsection{Denmark}

In Denmark TeliaSonera - the fourth largest mobile operator-purchased the thirdranked Orange in 2004, which led to a combined market share of around $20 \%$. The merger took place in a period when Denmark already had the lowest mobile telephony prices in the EU, as well as one of the highest churn rates. TeliaSonera was ranked third after the merger and was expected to challenge the market leaders-TDC and Sonofon-as TeliaSonera intended to expand its customer base and cut costs by closing down one of the networks. The merger was cleared by the 
Table 6 Price and investment effects of the first Dutch merger

\begin{tabular}{|c|c|c|c|c|c|c|c|c|}
\hline & \multicolumn{4}{|l|}{ RPM } & \multicolumn{4}{|l|}{ Capex } \\
\hline & \multicolumn{2}{|l|}{ Merging } & \multicolumn{2}{|l|}{ Rivals } & \multicolumn{2}{|l|}{ Merging } & \multicolumn{2}{|l|}{ Rivals } \\
\hline & Coeff. & SE & Coeff. & SE & Coeff. & SE & Coeff. & SE \\
\hline Merging/rival & -0.004 & 0.005 & $0.026^{* * * *}$ & 0.006 & $0.275^{*}$ & 0.122 & $0.294 *$ & 0.123 \\
\hline Minutes of use & $-0.000 * * *$ & 0.000 & $-0.000 * * *$ & 0.000 & $0.003 * * *$ & 0.001 & $0.003 * * *$ & 0.001 \\
\hline Mobile penetration & -0.007 & 0.008 & -0.005 & 0.008 & $1.349 * * *$ & 0.137 & $1.388 * * *$ & 0.137 \\
\hline Fixed penetration & 0.033 & 0.022 & 0.027 & 0.022 & $0.799 *$ & 0.328 & 0.619 & 0.323 \\
\hline GDP p.c. & $0.002 * * *$ & 0.000 & $0.002 * * *$ & 0.000 & $0.012^{*}$ & 0.005 & $0.010^{*}$ & 0.005 \\
\hline Number of obs & 1690 & & 1733 & & 1051 & & 1098 & \\
\hline F-statistic & 186.655 & & 172.148 & & 87.087 & & 89.378 & \\
\hline F-test $p$ value & 0.000 & & 0.000 & & 0.000 & & 0.000 & \\
\hline R-squared & 0.867 & & 0.866 & & 0.807 & & 0.800 & \\
\hline Root MSE & 0.038 & & 0.038 & & 0.457 & & 0.463 & \\
\hline
\end{tabular}

Merging/Rival represents the treatment dummy variable: it equals 1 in the post-merger period for the merging firm in the Merging pane and for rival firms in the Rivals pane

$* p<0.05 ; * * p<0.01 ; * * * p<0.001$

competition authorities, as it did not appear to create or strengthen a dominant position, nor pose any other threat to effective competition in the Danish market for mobile telephony. ${ }^{15}$

Following the merger, there was a general price increase for both the merging firms and their rivals in Denmark (Table 5). The effect was stronger for the merger participants ( 7.3 cents) than for their rivals $(6.0$ cents). Note that while the merger in Denmark was technically 5-to-4, the fifth competitor, 3 (Hutchison), only accounted for $1 \%$ of the market (in fact, in its analysis of the case, the EU Commission describes this as a four-entity market), and the change in concentration was in the nature of a 4-to-3 merger.

The Capex results imply that both merging firms and their rivals significantly increase investment spending after the merger. Thus, the Danish merger results also indicate a tradeoff between static and dynamic efficiencies; while Danish operators raised prices after the merger, they also increased infrastructure investments.

\subsection{Netherlands}

In 2005, the incumbent and market leader KPN acquired Telfort (which was ranked $3 \mathrm{rd}$ at that time). While the merged entity was expected to account for about $50 \%$ of the market, the merger was cleared unconditionally by the Dutch competition

15 Case No COMP/M.3530. TELIASONERA AB/ORANGE A/S. Commission decision of September 24, 2004, available at http://ec.europa.eu/competition/mergers/cases/decisions/m3530_en.pdf. 
Table 7 Price and investment effects of the second Dutch merger

\begin{tabular}{|c|c|c|c|c|c|c|c|c|}
\hline & \multicolumn{4}{|l|}{ RPM } & \multicolumn{4}{|l|}{ Capex } \\
\hline & \multicolumn{2}{|l|}{ Merging } & \multicolumn{2}{|l|}{ Rivals } & \multicolumn{2}{|l|}{ Merging } & \multicolumn{2}{|l|}{ Rivals } \\
\hline & Coeff. & SE & Coeff. & SE & Coeff. & SE & Coeff. & SE \\
\hline Merging/Rival & -0.002 & 0.005 & 0.001 & 0.006 & $0.373 *$ & 0.176 & $0.293^{*}$ & 0.146 \\
\hline Minutes of Use & $-0.000 * * *$ & 0.000 & $-0.000 * * *$ & 0.000 & $0.003 * * *$ & 0.001 & $0.003 * * *$ & 0.001 \\
\hline Mobile Penetration & $0.017 *$ & 0.007 & 0.006 & 0.007 & $1.377 * * *$ & 0.158 & $1.351 * * *$ & 0.151 \\
\hline Fixed Penetration & 0.024 & 0.031 & 0.027 & 0.030 & 1.107 & 0.640 & 1.107 & 0.636 \\
\hline GDP p.c. & $0.001 * * *$ & 0.000 & $0.001 * * *$ & 0.000 & $0.011 *$ & 0.006 & 0.010 & 0.006 \\
\hline Number of obs & 817 & & 839 & & 728 & & 741 & \\
\hline F-statistic & 184.900 & & 177.615 & & 113.049 & & 112.731 & \\
\hline F-test $p$ value & 0.000 & & 0.000 & & 0.000 & & 0.000 & \\
\hline R-squared & 0.826 & & 0.826 & & 0.831 & & 0.827 & \\
\hline Root MSE & 0.019 & & 0.019 & & 0.423 & & 0.423 & \\
\hline
\end{tabular}

Merging/Rival represents the treatment dummy variable: It equals 1 in the post-merger period for the merging firm in the Merging pane and for rival firms in the Rivals pane

$* p<0.05 ; * * p<0.01 ; * * * p<0.001$

authority on the grounds that the remaining three operators in the Netherlands-one of the few remaining countries with five carriers at that time-were all subsidiaries of strong international players capable to exert sufficient competitive pressure to prevent the creation or strengthening of a dominant position.

The Dutch market then experienced the second merger in 2007, when T-Mobile acquired Orange. The European Commission concluded that Orange was not a price maverick, as it was mostly active in the prepaid segment-unlike the rest of the carriers-and was not seen as a close substitute to T-Mobile. Nor was a collective dominant position by the three remaining operators expected to be a likely threat.

The case of the Netherlands is unique in our study in that its market was exposed to two successive mergers. This is interesting from the perspective of the commonly stated hypothesis that 4-to-3 mergers are significantly more harmful than 5-to-4 mergers (see, e.g., Csorba 2015).

It is important to mention that the analysis is somewhat complicated in the case of the Netherlands: Identifying the merger effects here is more problematic due to the overlap of the pre- and post-merger periods, as the close succession of the second merger (approximately 2 years after the first one) makes it difficult to disentangle the effects of each event.

The results that we report for the Dutch market (Tables 6,7) suggest that the effect on investment was substantially more pronounced, as is evidenced by statistically significant (albeit only at the 10\% level) and positive coefficients for both the merging firms and the rivals for both mergers, while for price we observe only an increase in the rivals' prices following the first merger. These results are robust to modifying the definitions of pre- and post-merger periods between the two mergers; 
Table 8 Price and investment effects of the Greek merger

\begin{tabular}{|c|c|c|c|c|c|c|c|c|}
\hline & \multicolumn{4}{|l|}{ RPM } & \multicolumn{4}{|l|}{ Capex } \\
\hline & \multicolumn{2}{|l|}{ Merging } & \multicolumn{2}{|l|}{ Rivals } & \multicolumn{2}{|l|}{ Merging } & \multicolumn{2}{|l|}{ Rivals } \\
\hline & Coeff. & SE & Coeff. & SE & Coeff. & SE & Coeff. & SE \\
\hline Merging/Rival & $-0.109 * * *$ & 0.017 & $-0.119 * * *$ & 0.018 & -0.027 & 0.263 & -0.169 & 0.175 \\
\hline Minutes of Use & $-0.000 * * *$ & 0.000 & $-0.001 * * *$ & 0.000 & $0.003 * * *$ & 0.001 & $0.003 * * *$ & 0.001 \\
\hline Mobile Penetration & -0.007 & 0.008 & $-0.021 * *$ & 0.008 & $1.352 * * *$ & 0.137 & $1.337 * * *$ & 0.132 \\
\hline Fixed Penetration & 0.015 & 0.023 & -0.018 & 0.025 & $0.751^{*}$ & 0.326 & $0.928 * *$ & 0.324 \\
\hline GDP p.c. & $0.002 * * *$ & 0.000 & $0.002 * * *$ & 0.000 & $0.012 *$ & 0.005 & $0.013 *$ & 0.005 \\
\hline Number of obs & 1684 & & 1722 & & 1050 & & 1078 & \\
\hline F-statistic & 165.946 & & 165.057 & & 89.312 & & 87.942 & \\
\hline F-test $p$ value & 0.000 & & 0.000 & & 0.000 & & 0.000 & \\
\hline R-squared & 0.868 & & 0.860 & & 0.810 & & 0.804 & \\
\hline Root MSE & 0.039 & & 0.042 & & 0.459 & & 0.460 & \\
\hline
\end{tabular}

Merging/Rival represents the treatment dummy variable: It equals 1 in the post-merger period for the merging firm in the Merging pane and for rival firms in the Rivals pane

$* p<0.05 ; * * p<0.01 ; * * * p<0.001$

but due to the aforementioned constraints, there is not too much room for resetting the date in the alternative specifications.

Thus, we again observe some trade-off between static and dynamic efficienciesat least for the first merger, where an increase in the prices of the rivals was accompanied by a higher level of the investment expenditures. But the exact distinction between the effects of the first and the second merger is difficult in the Dutch case.

\subsection{Greece}

In Greece, TIM Hellas - the third largest operator-acquired Q-Telecommunication: the youngest and the smallest entity in the market. TIM Hellas continued to be the third-largest operator after the merger. Even though the merger led to a reduction in the number of carriers from four to three, it was not expected to raise competition concerns, as Q-Telecom was not regarded as a price maverick, and, moreover, it was expected that TIM Hellas would compete more actively with the two large incumbents. The EU competition authority approved the merger. ${ }^{16}$

The estimated merger effect on prices in Greece was unambiguously negative (Table 8): both for the merging operators and their rivals. This result can be explained by the fact that, in line with the market description above, having acquired a larger share of the post-merger market, the third-ranked operator switched to a

16 Case No COMP/M.4036. TPG IV/APAX/Q-TELECOM. Commission decision of January 13, 2006, available at http://ec.europa.eu/competition/mergers/cases/decisions/m4036_20060113_20310_en.pdf. 
more aggressive behavior to challenge the two big entities and gain a larger sharewhich at the same time triggered a symmetric response by the incumbents.

While the prices clearly decreased after the merger, the estimated coefficients from the Capex equations are negative but not statistically significant. Thus, the Greek merger neither supports nor refutes the hypothesized tradeoff between static and dynamic efficiencies.

\subsection{Summary of the Merger Results}

Overall, the estimation results suggest that-while most of the wireless markets experienced a decrease in prices over the corresponding period-this effect was softened by weaker competition in some markets that were exposed to mergers. In three out of the five mergers that we analyze, weaker competition led to higher prices that were charged by the merging firms In two cases, however-in Austria and Greecemergers led to a further decrease in the prices of the merging firms and/or rivals. This can be explained at least to some extent by the specificities of these mergers. In the Austrian case - thanks to the remedies attached to the merger- $\mathrm{H} 3 \mathrm{G}$ (the smallest carrier in the market) was significantly strengthened by acquiring that network infrastructure and frequencies that it needed to challenge the other operators. In the Greek case, the third-largest operator was also significantly strengthened by acquiring the fourth-largest one.

Further, our results suggest a positive relation between the estimated effects of mergers on prices and on investment. In all four of the markets that we studied, the direction of the effects on prices and investments was the same: Higher prices coincide with higher investment, and lower prices with lower investment. ${ }^{17}$ This suggests that the effect of mergers on consumer welfare extends beyond the price changes and includes, among others, dynamic effects that result from higher levels of investments. These dynamic effects also need to be given proper consideration in the merger evaluation process. In the case of mobile telecommunications market in Europe, all mergers over the last 2 decades resulted in efficiencies, either static or dynamic, but never both at the same time. Moreover, the static and dynamic efficiencies seem to be negatively correlated, which poses a difficult dilemma for merger policy.

As discussed before, we test the validity of our results by inspecting the premerger price and investment paths and checking whether they exhibit common trends. In addition, we plot the residuals from the price regressions with the use of the the same set of controls in the pre-merger period and examine whether the prices follow similar trends conditional on the covariates in our model. These figures (Appendix 2) largely justify our approach.

\footnotetext{
17 One possible mechanism for our result that prices and investment move in the same direction is that investment simply gets more attractive if prices and therefore profit opportunities are higher. Another possibility is that telecom companies are financially constrained; when prices increase, they have the funds to undertake investments that they would have made earlier, but could not finance (see Hall 1995).
} 
We performed further robustness checks where we included additional controls, such as the share of pre-paid customers, fixed line prices, and time since the entry into the market. We also used different definitions of the merger date to account for the fact that the time period between the announcement of the intention to merge and the actual legal, corporate, and marketing changes can span several quarters. However, we find similar effects.

We also estimated specifications where the post-merger period is split in two parts: 2 years immediately after the merger and the subsequent years. First, this allows us to analyze how fast the effect is building up. Second, it could serve as an additional validation check, as the potential deviations in the short-term estimates from the overall results would suggest that the overall effect could possibly have been driven by factors that were unrelated to the merger.

We report the results in Appendix 3, where the dummy variables Merging08/ Rival08 and Merging8+/Rival8+ are defined in an analogous way to Merging/Rival, except that they take the value 1 only in the first eight quarters after the merger and only after the first eight quarters after the merger, correspondingly. As the overall effects are similar, in both the short and long term, with the latter being larger in absolute value in most cases, we conclude that the obtained estimates are consistent with the assumption that the effect accumulates over time as the merging firms complete the consolidation and restructuring processes and their rivals internalize those processes in their responses.

\section{Conclusion}

We conducted an ex-post evaluation of five domestic horizontal mergers in the European wireless sector. These markets can be characterized as: national in scope; displaying large market concentration; and in need of large sunk investments. Thus, they represent an ideal testing ground for an ex-post evaluation of merger effects on static and dynamic efficiencies. The evidence from the Netherlands and Denmark supports the conventional wisdom of mergers being associated with a higher price level for consumers. Thus, we provide evidence that no two mergers are the same, and although post-merger price increases often occur, many other factors that reflect the particular setting in which a merger takes place and the specifics of each case have to be accounted for. In particular, the Austrian and Greek cases suggest that strengthening small firms by either allowing them to merge or imposing appropriate remedies in a merger process may lead to downward pressure on prices.

Focusing on the effects of mergers on prices alone, however, ignores important issues, such as changes in product choice and service quality that can have a mitigating effect on consumer welfare. Particularly, the growth in data services has become an important feature of the services that have been offered by mobile carriers over the last decade with associated requirements of huge sunk capital expenditures. Therefore, we analyze both price and the investment effects of mergers: We examine the issue of whether there is a trade-off between static (i.e. price) and dynamic (i.e. investment) efficiency. 
We find that for the five mergers under scrutiny, prices and investment move in the same direction: For those mergers where we find a dominance of market power effects (Netherlands and Denmark), we also find significant increases in investment spending post-merger. For mergers where we find a preponderance of cost efficiency (Austria and Greece), we do not find significant increases in post-merger investment spending. Thus, we find evidence of a trade-off between static and dynamic efficiencies in mergers in a large sunk cost industry.

The fact that mergers do not uniformly lead to an increase or decrease in prices, but that investments more in the same direction as prices suggests a powerful link between the two: While the specificities of each merger may lead to different outcomes overall, the tradeoff between static and dynamic efficiency remains.

Acknowledgements Open access funding provided by Vienna University of Economics and Business (WU). Thanks to participants of the INSEAD Conference on Business and Public Policy, the VGSE microeconomic seminar (Vienna Graduate School of Economics), and EARIE.

Open Access This article is distributed under the terms of the Creative Commons Attribution 4.0 International License (http://creativecommons.org/licenses/by/4.0/), which permits unrestricted use, distribution, and reproduction in any medium, provided you give appropriate credit to the original author(s) and the source, provide a link to the Creative Commons license, and indicate if changes were made.

\section{Appendices}

\section{Appendix 1: Descriptive Statistics}

See Tables 9 and 10. 
Table 9 Summary statistics by country

\begin{tabular}{lrrrrllllr}
\hline Country & N obs & RPM & Capex & N firms & $\begin{array}{l}\text { Minutes of } \\
\text { use }\end{array}$ & Mobile Pen. & Fixed Pen. & GDP p.c. \\
\hline Austria & 227 & 0.231 & 32.397 & 3.890 & 151.332 & 0.254 & 0.448 & 32,631 \\
Belgium & 153 & 0.180 & 37.485 & 2.941 & 137.8064 & 0.270 & 0.462 & 31,155 \\
Czech Repub- & 165 & 0.180 & 30.052 & 2.855 & 107.9457 & 0.325 & 0.298 & 10,871 \\
$\quad$ lic & & & & & & & & \\
Denmark & 240 & 0.184 & 20.094 & 4.233 & 161.5359 & 0.233 & 0.603 & 41,036 \\
France & 153 & 0.181 & 212.581 & 3.000 & 229.8033 & 0.230 & 0.579 & 30,145 \\
Germany & 204 & 0.256 & 156.514 & 3.980 & 99.01981 & 0.222 & 0.647 & 29,935 \\
Greece & 189 & 0.290 & 37.269 & 3.212 & 121.1627 & 0.309 & 0.498 & 19,419 \\
Hungary & 153 & 0.168 & 21.432 & 2.843 & 150.2849 & 0.272 & 0.337 & 10,369 \\
Italy & 204 & 0.203 & 184.250 & 3.627 & 126.7617 & 0.303 & 0.433 & 26,374 \\
Netherlands & 255 & 0.237 & 44.134 & 4.196 & 141.9986 & 0.213 & 0.517 & 33,046 \\
Norway & 120 & 0.207 & 25.252 & 2.600 & 198.6554 & 0.368 & 0.526 & 55,160 \\
Poland & 171 & 0.214 & 58.421 & 3.398 & 99.12053 & 0.199 & 0.281 & 7814 \\
Portugal & 153 & 0.201 & 38.558 & 3.000 & 125.6226 & 0.356 & 0.408 & 15,362 \\
Spain & 181 & 0.214 & 112.540 & 3.420 & 145.8192 & 0.261 & 0.439 & 23,564 \\
Sweden & 204 & 0.210 & 19.679 & 3.647 & 158.7789 & 0.274 & 0.645 & 35,187 \\
Switzerland & 153 & 0.271 & 45.063 & 2.902 & 116.7843 & 0.307 & 0.700 & 43,161 \\
United King- & 250 & 0.216 & 147.779 & 4.580 & 160.7919 & 0.208 & 0.569 & 35,106 \\
$\quad$ dom & & & & & & & & & \\
$\quad$ Total (N obs)/ & 3175 & 0.215 & 82.111 & 3.542 & 143.405 & 0.265 & 0.499 & 28,533 \\
$\quad$ Mean & & & & & & & & \\
\hline
\end{tabular}

Table 10 Market concentration before/after the merger

\begin{tabular}{llrll}
\hline & HHI before & $\Delta$ HHI & HHI 1 year after & HHI 2 years after \\
\hline Austria & 3008 & 272 & 3219 & 3233 \\
Denmark & 3372 & 240 & 3593 & 3618 \\
Netherlands 1 & 2374 & 1070 & 3423 & 3465 \\
Netherlands 2 & 3465 & 361 & 3726 & 3772 \\
Greece & 3112 & 275 & 3396 & 3382 \\
\hline
\end{tabular}

\section{Appendix 2: Common Trends}

The key assumption that underlies the validity of the difference-in-difference approach is that the outcome of interest in the treatment and control groups would follow the same time trend in the absence of treatment. While it is generally difficult to ascertain whether this assumption holds, one way to do it-which has been previously suggested in the literature (see, e.g., Hastings 2004)—is simply visually to inspect both trends in the pre-treatment period: If they appear to be parallel (the means, of course, do not have to be the same), one would hope that 
the control group's post-treatment path would also be parallel to the unobserved counterfactual.

One must also keep in mind that, in order for that to hold, the intervention should not influence the units in the control group. In our context, a domestic mobile carrier merger in a given market should not influence the outcomes in other countries. We expect this to be the case due to the fact that wireless markets in Europe are rather distinct because of the still national regulatory structure.

Below we depict the price and investments paths of RPM and Capex, which are observed over the timespan that is available in our dataset in the treatment (the merging firm) and control groups (the average across all operators in the countries where no merger took place). In addition, we also account for the possibility that - even if not parallel in general - the price and investment trends could still be parallel conditional on a set of regressors: Including these regressors then in the main model would prevent it from being invalidated based on the pre-treatment trends divergence. Therefore, we also plot the residuals from the regressions that are based on the same specification as in our merger effects model.

\section{Merging}

See Figs. 2, 3, 4 and 5.

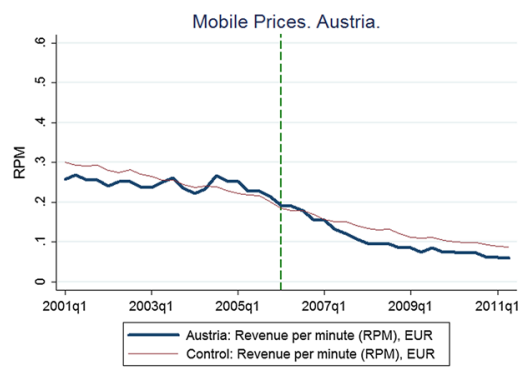

(a) RPM

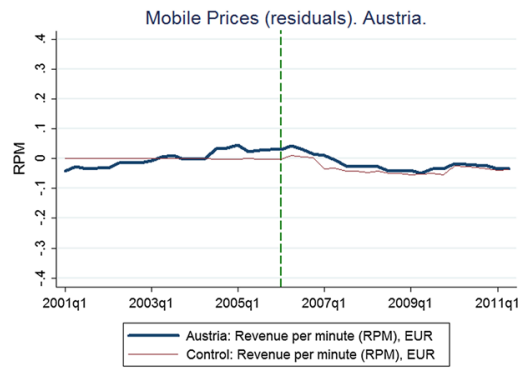

(c) RPM residuals

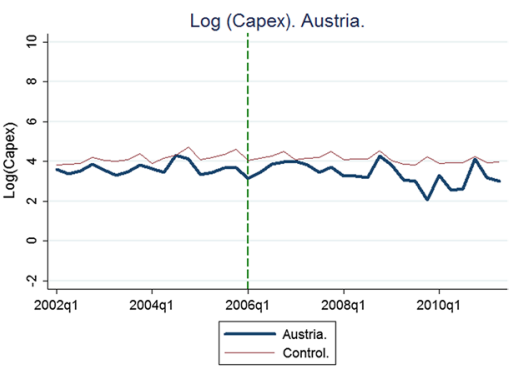

(b) $\log ($ Capex $)$

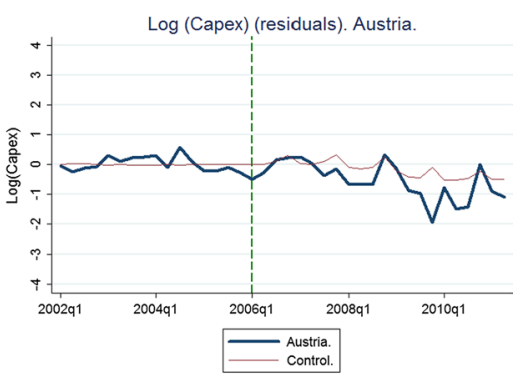

(d) $\log$ (Capex) residuals.

Fig. 2 Austria 


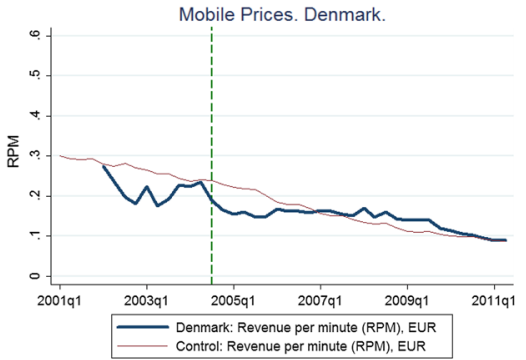

(a) RPM.

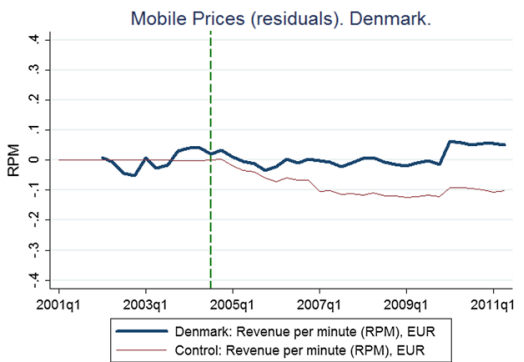

(c) RPM residuals.

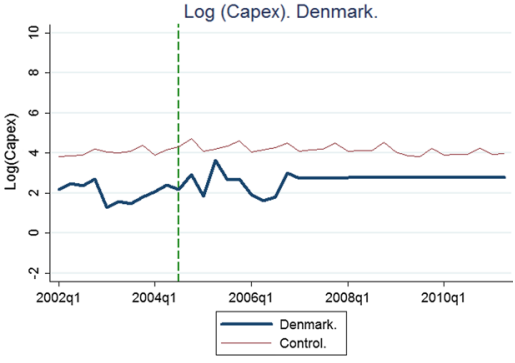

(b) $\log ($ Capex) .

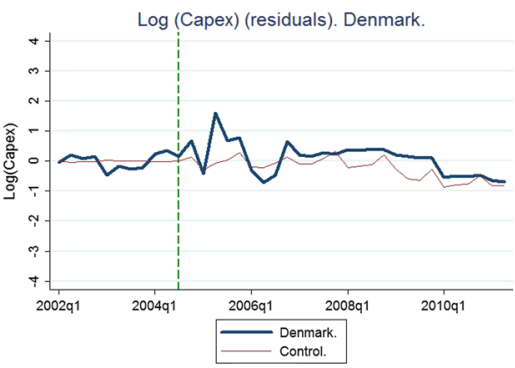

(d) $\log$ (Capex) residuals.

Fig. 3 Denmark

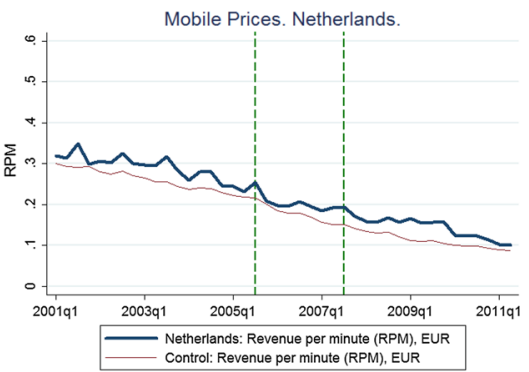

(a) RPM.

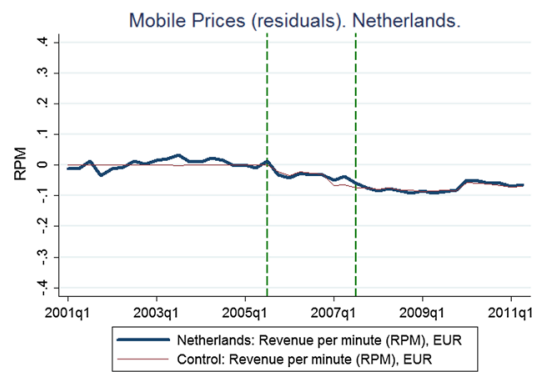

(c) RPM residuals

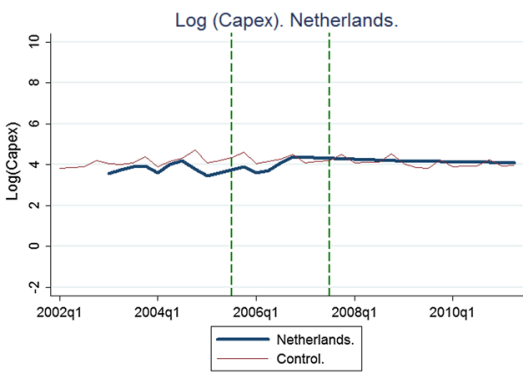

(b) $\log ($ Capex)

Log (Capex) (residuals). Netherlands.

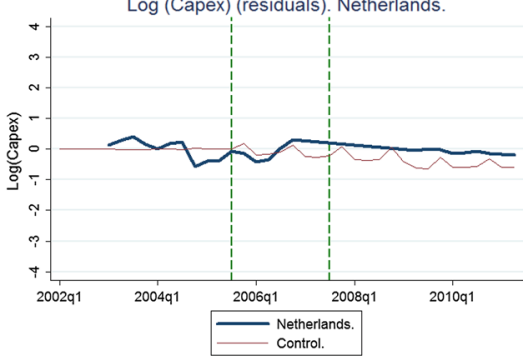

(d) $\log ($ Capex $)$ residuals.

Fig. 4 Netherlands 


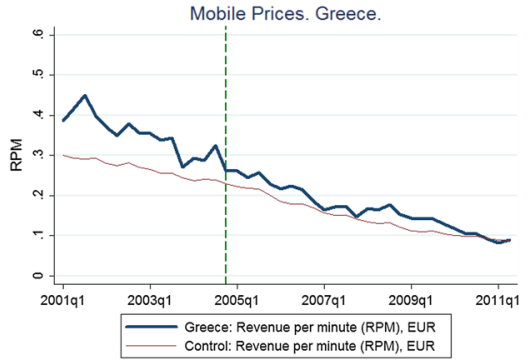

(a) RPM.

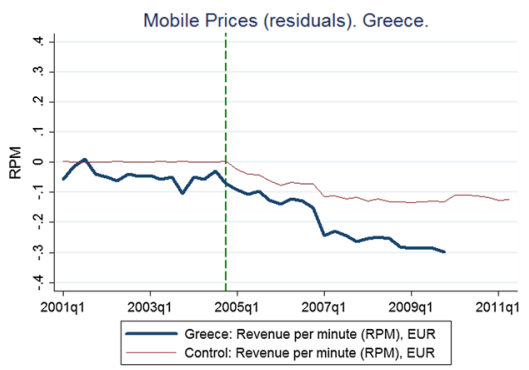

(c) RPM residuals

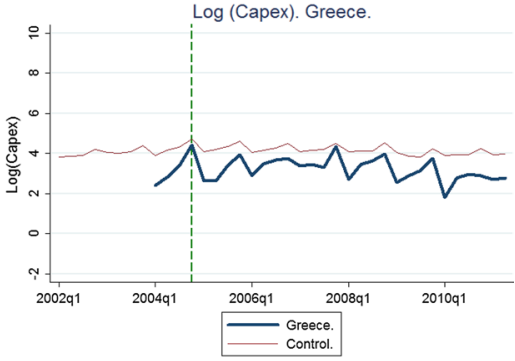

(b) $\log ($ Capex) .

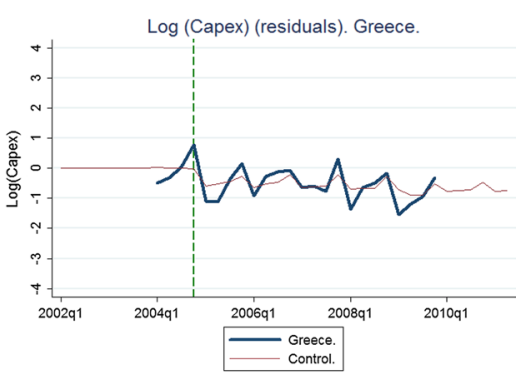

(d) $\log ($ Capex $)$ residuals.

Fig. 5 Greece

\section{Rivals}

See Figs. 6, 7, 8 and 9.

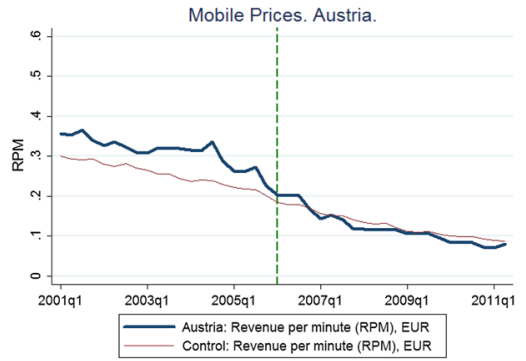

(a) RPM.

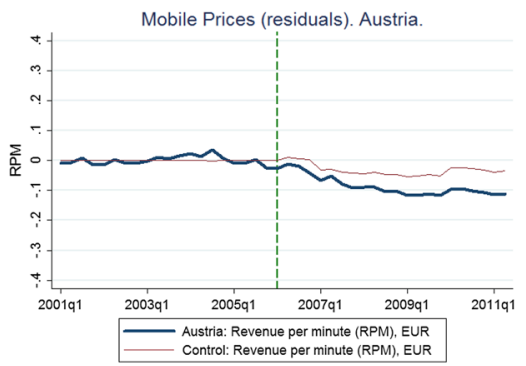

(c) RPM residuals.

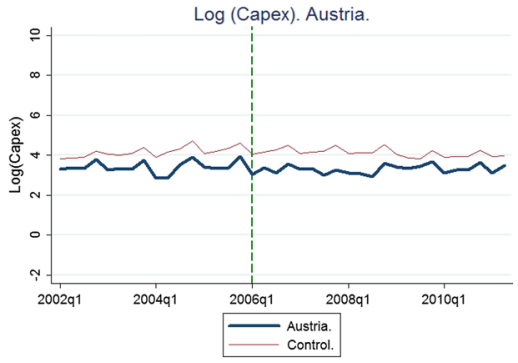

(b) $\log ($ Capex) .

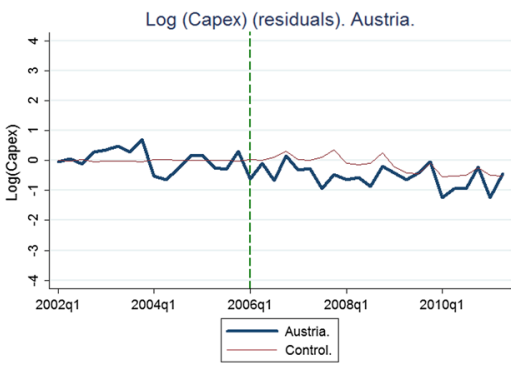

(d) $\log ($ Capex $)$ residuals.

Fig. 6 Austria. Rivals 


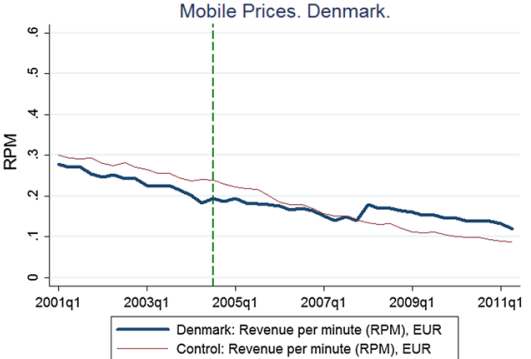

(a) RPM.

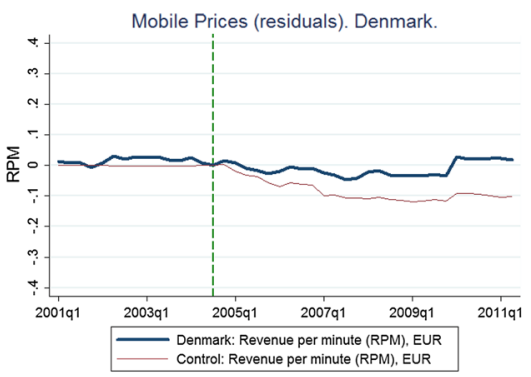

(c) RPM residuals,

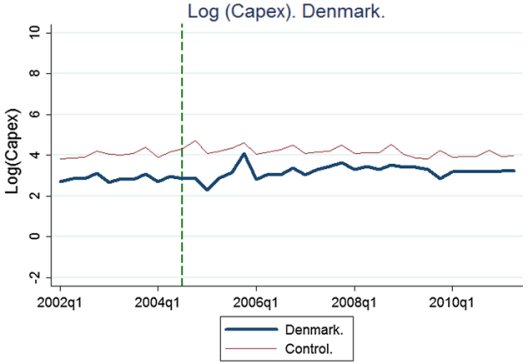

(b) $\log ($ Capex)

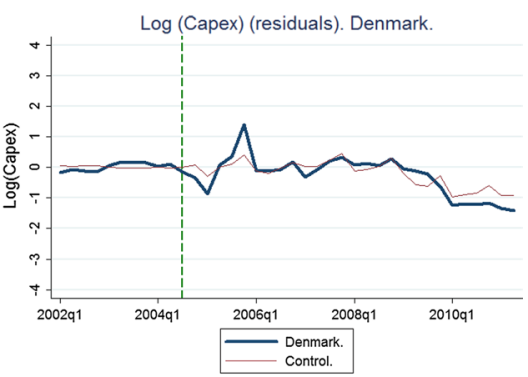

(d) $\log$ (Capex) residuals.

Fig.7 Denmark. Rivals

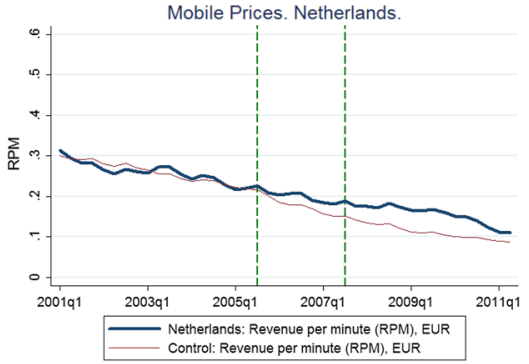

(a) RPM.

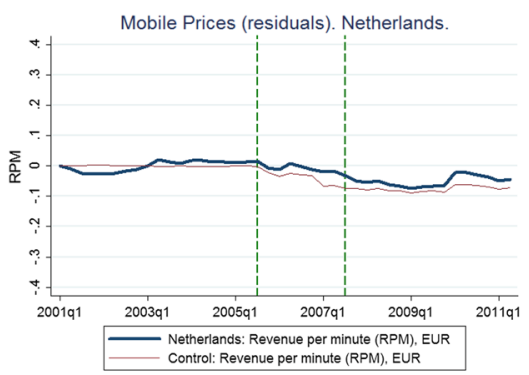

(c) RPM residuals.

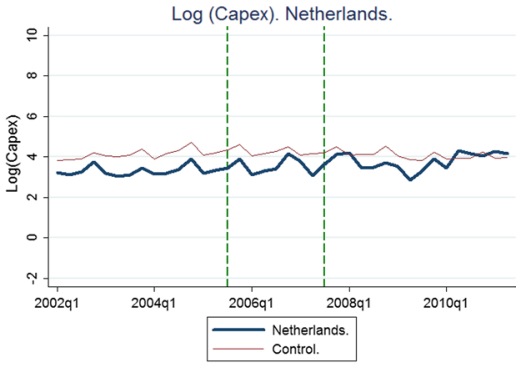

(b) $\log ($ Capex $)$.

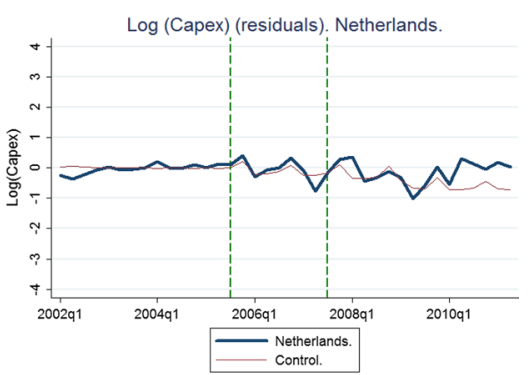

(d) $\log$ (Capex) residuals.

Fig. 8 Netherlands. Rivals 


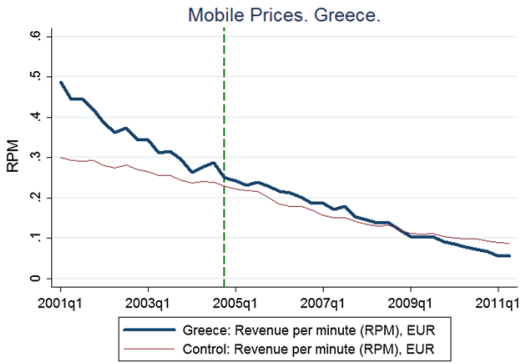

(a) RPM.

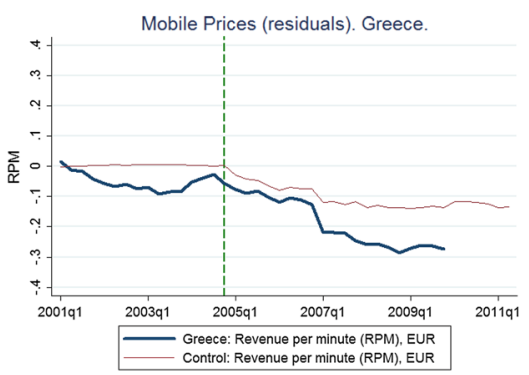

(c) RPM residuals

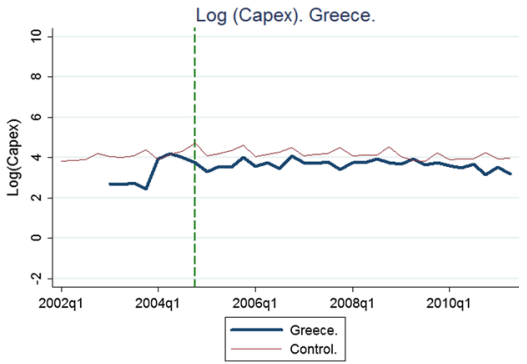

(b) $\log ($ Capex $)$

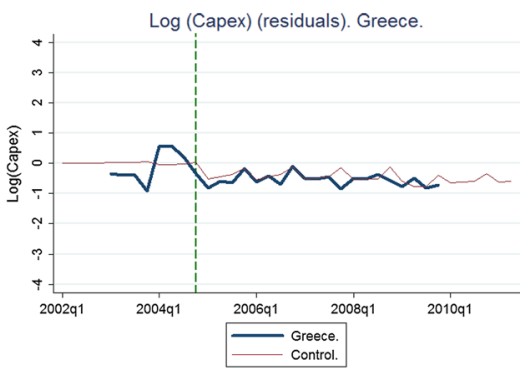

(d) $\log ($ Capex) residuals.

Fig. 9 Greece. Rivals

\section{Appendix 3: Short- and Long-Term Effects}

See Table 11. 
Table 11 Short- and long-term merger effects

\begin{tabular}{|c|c|c|c|c|c|c|c|c|}
\hline & \multicolumn{4}{|l|}{ RPM } & \multicolumn{4}{|l|}{ Capex } \\
\hline & \multicolumn{2}{|l|}{ Merging } & \multicolumn{2}{|l|}{ Rivals } & \multicolumn{2}{|l|}{ Merging } & \multicolumn{2}{|l|}{ Rivals } \\
\hline & Coeff. & SE & Coeff. & SE & Coeff. & SE & Coeff. & SE \\
\hline \multicolumn{9}{|l|}{ Austria } \\
\hline Merging/Rival & 0.006 & 0.006 & $-0.061 * * *$ & 0.006 & $-0.297^{*}$ & 0.130 & $-0.333 * *$ & 0.123 \\
\hline Merging08/Rival08 & 0.012 & 0.007 & $-0.047 * * *$ & 0.006 & -0.067 & 0.124 & $-0.392 *$ & 0.153 \\
\hline $\begin{array}{l}\text { Merging8+/Rival8+ } \\
\text { Denmark }\end{array}$ & 0.001 & 0.006 & $-0.069 * * *$ & 0.005 & $-0.441^{* *}$ & 0.165 & $-0.296^{*}$ & 0.132 \\
\hline Merging/Rival & $0.073 * * *$ & 0.012 & $0.060 * * *$ & 0.008 & $0.470 * * *$ & 0.130 & $0.310 * *$ & 0.103 \\
\hline Merging08/Rival08 & $0.030 * *$ & 0.012 & $0.032 * * *$ & 0.009 & 0.001 & 0.217 & -0.055 & 0.167 \\
\hline $\begin{array}{l}\text { Merging8+/Rival8+ } \\
\text { Netherlands }\end{array}$ & $0.091 * * *$ & 0.010 & $0.075^{* * *}$ & 0.008 & $0.676^{* * * *}$ & 0.109 & $0.530 * * *$ & 0.088 \\
\hline Merging/Rival & -0.004 & 0.005 & $0.026 * * *$ & 0.006 & $0.275^{*}$ & 0.122 & $0.294 *$ & 0.123 \\
\hline Merging08/Rival08 & -0.004 & 0.006 & $0.025^{* * *}$ & 0.006 & -0.030 & 0.135 & 0.145 & 0.126 \\
\hline $\begin{array}{l}\text { Merging8+/Rival8+ } \\
\text { Netherlands2 }\end{array}$ & -0.004 & 0.005 & $0.027 * * *$ & 0.006 & $0.445^{* * * *}$ & 0.107 & $0.381 * *$ & 0.146 \\
\hline Merging/Rival & -0.002 & 0.005 & 0.001 & 0.006 & $0.373^{*}$ & 0.176 & $0.293^{*}$ & 0.146 \\
\hline Merging08/Rival08 & -0.004 & 0.005 & 0.003 & 0.006 & 0.307 & 0.238 & -0.048 & 0.168 \\
\hline $\begin{array}{l}\text { Merging8+/Rival8+ } \\
\text { Greece }\end{array}$ & -0.000 & 0.005 & -0.002 & 0.007 & $0.445^{*}$ & 0.201 & $0.543 * * *$ & 0.153 \\
\hline Merging/Rival & $-0.109 * * *$ & 0.017 & $-0.119 * * *$ & 0.018 & -0.027 & 0.263 & -0.169 & 0.175 \\
\hline Merging08/Rival08 & $-0.091 * * *$ & 0.017 & $-0.101 * * *$ & 0.018 & -0.078 & 0.282 & -0.168 & 0.211 \\
\hline Merging8+/Rival8+ & $-0.121^{* * *}$ & 0.017 & $-0.132 * * *$ & 0.019 & 0.008 & 0.272 & -0.170 & 0.177 \\
\hline
\end{tabular}

Merging/Rival represents the treatment dummy variable: It equals 1 in the post-merger period for the merging firm in the left panel and for rival firms in the right panel. Merging08/Rival08 and Merging8+/ Rival $8+$ are analagous, except that they equal 1 only in the first 8 quarters after the merger and only after the first 8 quarters after the merger, correspondingly

$* p<0.05 ; * * p<0.01 ; * * * p<0.001$

\section{References}

Aghion, P., Bloom, N., Blundell, R., Griffith, R., \& Howitt, P. (2005). Competition and innovation: An inverted-U relationship. The Quarterly Journal of Economics, 120(2), 701-728.

Aguzzoni, L., Buehler, B., Di Martile, L., Ecker, G., Kemp, R., Schwarz, A., et al. (2015). Ex-post analysis of two mobile telecom mergers: T-Mobile/tele. ring in Austria and T-Mobile/Orange in the Netherlands. DG COMP: Report of the European Commission.

Ahuja, G., \& Katila, R. (2001). Technological acquisitions and the innovation performance of acquiring firms: A longitudinal study. Strategic Management Journal, 22(3), 197-220.

Beneito, P. (2003). Choosing among alternative technological strategies: An empirical analysis of formal sources of innovation. Research Policy, 32(4), 693-713.

BofA Merrill Lynch. Global Wireless Matrix. 1Q2010.

Bresnahan, T. F., \& Trajtenberg, M. (1995). General purpose technologies 'Engines of growth'? Journal of Econometrics, 65(1), 83-108. 
Cassiman, B., Colombo, M. G., Garrone, P., \& Veugelers, R. (2005). The impact of M\&A on the R\&D process: An empirical analysis of the role of technological-and market-relatedness. Research Policy, 34(2), 195-220.

Chatterjee, S. (1986). Types of synergy and economic value: The impact of acquisitions on merging and rival firms. Strategic Management Journal, 7(2), 119-139.

Cloodt, M., Hagedoorn, J., \& Van Kranenburg, H. (2006). Mergers and acquisitions: Their effect on the innovative performance of companies in high-tech industries. Research Policy, 35(5), 642-654.

Clougherty, J. A., \& Duso, T. (2011). Using rival effects to identify synergies and improve merger typologies. Strategic Organization, 9(4), 310-335.

Coad, A., \& Rao, R. (2008). Innovation and firm growth in high-tech sectors: A quantile regression approach. Research Policy, 37(4), 633-648.

Cohen, W. M., \& Levin, R. C. (1989). Empirical studies of innovation and market structure. Handbook of Industrial Organization, 2, 1059-1107.

Connor, R. A., Feldman, R. D., \& Dowd, B. E. (1998). The effects of market concentration and horizontal mergers on hospital costs and prices. International Journal of the Economics of Business, 5(2), $159-180$.

Csorba, G. (2015). Does one more or one less mobile operator affect prices?: A comprehensive ex-post evaluation of entries and mergers in European mobile telecommunication markets. MTA KRTK Mühelytanulmányok

Czernich, N., Falck, O., Kretschmer, T., \& Woessmann, L. (2011). Broadband infrastructure and economic growth. The Economic Journal, 121(552), 505-532.

Dafny, L. (2009). Estimation and identification of merger effects: An application to hospital mergers. The Journal of Law and Economics, 52(3), 523-550.

De Faria, P., Lima, F., \& Santos, R. (2010). Cooperation in innovation activities: The importance of partners. Research Policy, 39(8), 1082-1092.

Desyllas, P., \& Hughes, A. (2010). Do high technology acquirers become more innovative? Research Policy, 39(8), 1105-1121.

Duso, T., Neven, D. J., \& Röller, L.-H. (2007). The political economy of European merger control: Evidence using stock market data. The Journal of Law and Economics, 50(3), 455-489.

Eckbo, B. E. (1983). Horizontal mergers, collusion, and stockholder wealth. Journal of Financial Economics, 11(1-4), 241-273.

Economides, N., Seim, K., \& Viard, V. B. (2008). Quantifying the benefits of entry into local phone service. The RAND Journal of Economics, 39(3), 699-730.

European Commission. Case No COMP/M.3530. TELIASONERA AB/ORANGE A/S. Commission decision of September 24 (2004). http://ec.europa.eu/competition/ mergers/cases/decisions/m3530 _en.pdf.

European Commission. Case No COMP/M.3916. T-MOBILE AUSTRIA/TELE.RING. Commission decision of April 26 (2006a). http://ec.europa.eu/competition/mergers/cases/decisions/m3916 _20060426_20600_en.pdf.

European Commission. Case No COMP/M.4036. TPG IV/APAX/Q-TELECOM. Commission decision of January 13 (2006b). http://ec.europa.eu/competition/mergers/cases/decisions/m4036_20060 113_20310_en.pdf.

Focarelli, D., \& Panetta, F. (2003). Are mergers beneficial to consumers? Evidence from the market for bank deposits. The American Economic Review, 93(4), 1152-1172.

Genakos, C., Valletti, T., \& Verboven, F. (2018). Evaluating market consolidation in mobile communications. Economic Policy, 33(93), 45-100.

Grajek, M., \& Röller, L.-H. (2012). Regulation and investment in network industries: Evidence from European telecoms. The Journal of Law and Economics, 55(1), 189-216.

Greenstein, S., \& Mazzeo, M. (2006). The role of differentiation strategy in local telecommunication entry and market evolution: 1999-2002. The Journal of Industrial Economics, 54(3), 323-350.

Gugler, K., \& Szücs, F. (2016). Merger externalities in oligopolistic markets. International Journal of Industrial Organization, 47, 230-254

Hall, B. H. (1995). Firm investment with liquidity constraints: What can the Euler equations tell us? Unpublished.

Hitt, M. A., Hoskisson, R. E., Johnson, R. A., \& Moesel, D. D. (1996). The market for corporate control and firm innovation. Academy of Management Journal, 39(5), 1084-1119.

McCabe, M. J. (2002). Journal pricing and mergers: A portfolio approach. The American Economic Review, 92(1), 259-269. 
Moatti, V., Ren, C. R., Anand, J., \& Dussauge, P. (2015). Disentangling the performance effects of efficiency and bargaining power in horizontal growth strategies: An empirical investigation in the global retail industry. Strategic Management Journal, 36(5), 745-757.

Morgan, E. J. (2001). Innovation and merger decisions in the pharmaceutical industry. Review of Industrial Organization, 19(2), 181-197.

Nardotto, M., Valletti, T., \& Verboven, F. (2015). Unbundling the incumbent: Evidence from UK broadband. Journal of the European Economic Association, 13(2), 330-362.

Oxley, J. E., Sampson, R. C., \& Silverman, B. S. (2009). Arms race or détente? How interfirm alliance announcements change the stock market valuation of rivals. Management Science, 55(8), 1321-1337.

Röller, L.-H., \& Waverman, L. (2001). Telecommunications infrastructure and economic development: A simultaneous approach. American Economic Review, 91, 909-923.

Sacco, D., \& Schmutzler, A. (2011). Is there a U-shaped relation between competition and investment? International Journal of Industrial Organization, 29(1), 65-73.

Scherer, F. M. (1998). Schumpeter and plausible capitalism. J. Reprints Antitrust L. \& Econ., $28,759$.

Servaes, H., \& Tamayo, A. (2013). How do industry peers respond to control threats? Management Science, 60(2), 380-399.

Seth, A. (1990). Sources of value creation in acquisitions: An empirical investigation. Strategic Management Journal, 11(6), 431-446.

Stillman, R. (1983). Examining antitrust policy towards horizontal mergers. Journal of Financial Economics, 11(1-4), 225-240.

Szücs, F. (2014). M\&A and R\&D: Asymmetric effects on acquirers and targets? Research Policy, 43(7), $1264-1273$.

Valentini, G. (2012). Measuring the effect of M\&A on patenting quantity and quality. Strategic Management Journal, 33(3), 336-346.

Wagner, M. (2011). To explore or to exploit? An empirical investigation of acquisitions by large incumbents. Research Policy, 40(9), 1217-1225.

Weinberg, M. (2007). The price effects of horizontal mergers. Journal of Competition Law and Economics, 4(2), 433-447.

Williamson, O. E. (1968). Economies as an antitrust defense: The welfare tradeoffs. The American Economic Review, 58(1), 18-36.

Zhao, X. (2009). Technological innovation and acquisitions. Management Science, 55(7), 1170-1183.

Publisher's Note Springer Nature remains neutral with regard to jurisdictional claims in published maps and institutional affiliations. 